\title{
HIDRODINÂMICA EM MEIO NÃO SATURADO: ESTUDO DE CASO NO AQUÍFERO LIVRE BARREIRAS
}

${ }^{1}$ Paulo Pontes Araújo; ${ }^{2}$ Francisco de Assis Oliveira; ${ }^{3}$ Herdjania Veras de Lima

Resumo: A área de pesquisa está localizada, município de Capitão Poço (PA). O objetivo deste trabalho foi estimar a taxa de infiltração em meio não saturado do aquífero Barreiras. Para tal, foram construídos 15 poços com 3 " de diâmetro e $2 \mathrm{~m}$ de profundidade. Nestes poços foram realizados 15 testes de infiltração, para a determinação da condutividade hidráulica do meio não saturado. Os resultados obtidos mostram que os sedimentos foram classificados como arenitos argilosos. A condutividade hidráulica variou de $6,75 \mathrm{~mm} \mathrm{~h}^{-1}$ a $7,05 \mathrm{~mm} \mathrm{~h}^{-1}$ e a porosidade entre $38 \%$ e $39 \%$. Estes valores são compatíveis com a litologia do meio não saturado do aquífero Barreiras. A classificação textural, os valores de condutividade hidráulica e o cálculo da taxa de infiltração no meio não saturado, associada com as medições do nível de água em poços piezômetros, próximo dos testes de infiltração, permitiu a indicação de que entre três e quatro meses, as águas subterrâneas podem ser afetadas adversamente por contaminantes dispostas na superfície. A taxa média de infiltração, no meio não saturado, foi estimada em cerca de $3 \mathrm{~mm} \mathrm{~h}^{-1}$.

Palavras-chave: meio não saturado, condutividade hidráulica, taxa de infiltração.

\section{HYDRODYNAMICS IN ENVIRONMENT INSATURATED: CASE STUDY IN AQUIFER BARRIERS}

\begin{abstract}
The research area is located in the Capitão Poço municipality (PA). The objective of this study was to estimate the infiltration rate in a non-saturated aquifer Barriers. To this end, were constructed 15 wells with a 3 " diameter and $2 \mathrm{~m}$ depth. These wells were carried out 15 infiltration tests for determining the hydraulic conductivity in environment not saturated. The results obtained show that the sediments were classified as argillaceous sandstones. Hydraulic conductivity varied from $6.75 \mathrm{~mm} \mathrm{~h} \mathrm{~mm}^{-1}$ to $7.05 \mathrm{~h}^{-1}$ and porosity varied $38 \%$ and $39 \%$. These values are compatible with the lithology of the environment unsaturated aquifer Barriers. Textural classification, the hydraulic conductivity values and the calculation of the leakage rate in the middle unsaturated associated with the water level measurements piezometers wells, near the infiltration tests, allowed the indication that between three and four months, groundwater can be adversely affected by contaminants disposed on the surface. The average rate of infiltration in environment unsaturated was estimated to be about $3 \mathrm{~mm} \mathrm{~h}^{-1}$.
\end{abstract}

Keywords: unsaturated, hydraulic conductivity, infiltration rate

\footnotetext{
${ }^{1}$ Serviço Geológico do Brasil-CPRM: Av. Dr. Freitas, 3645, Belém-PA, (091) 3182.1318, paulo.araujo@cprm.gov.br

${ }^{2 e} 3$ Universidade Federal Rural da Amazônia Av. Pres. Tancredo Neves, 2501, Belém-PA, (091) 3342.5786,

francisco.oliveira@ufra.edu.br; herdjania.lima@ufra.edu.br
} 


\section{1 - INTRODUÇÃO}

A área de pesquisa está localizada no município de Capitão Poço (nordeste do Pará), nas nascentes da microbacia do rio Capitão Pocinho. Este trabalho objetivou analisar a hidrodinâmica do meio não saturado do aquífero livre Barreiras.

Os fatores mais importantes que condicionam a taxa de infiltração dos contaminantes através do meio não saturado, até atingir a água subterrânea rasa, são os seguintes: a intensidade da precipitação pluviométrica, a composição litológica do solo, a condutividade hidráulica do meio não saturado, a porosidade total do meio não saturado e a profundidade do nível da água na zona saturada. Em grande parte os contaminantes que infiltram são adsorvidos pela matéria orgânica ou por fácies argilosas, impedindo que esses alcancem as águas subterrâneas pertencentes a aquíferos livres e/ou confinados drenantes. A textura e a porosidade também são determinantes na capacidade do solo em reter ou não os contaminantes (Khan, 1980).

A condutividade hidráulica do meio não saturado é um parâmetro fundamental na estimativa da taxa de infiltração das águas e, consequentemente, para equacionar os indicadores de susceptibilidade à poluição das águas subterrâneas. Sua determinação "in situ" sugere valores mais próximos da realidade do que aqueles determinados em laboratório.

A determinação da porosidade total do meio não saturado, na área de pesquisa, teve como finalidade a utilização desse parâmetro para a estimativa da taxa linear média do fluxo subterrâneo vertical. Uma vez que o aquífero é livre, o material que compõe a zona não saturada representa o próprio aquífero.

Arruda (1984) realizou um balanço hídrico do solo utilizando um infiltrômetro de $20 \mathrm{~m}^{2}$. Para tal foram ajustadas quatro equações matemáticas (Green Ampt, Horton, Philip e Smith), sendo que a de Horton obteve o melhor ajuste para os dados analisados. Foi observado que a taxa de infiltração inicial é função da classe de solo e da umidade atual. Além disso, o autor concluiu que a constante de decaimento da taxa de infiltração varia de acordo com a classe de solo analisado.

Raimbault et al. (2002) estudaram a variação espacial e temporal da infiltração analisando as mudanças do coeficiente de escoamento superficial, durante os períodos chuvosos, em uma mesma bacia hidrográfica. Neste estudo, foram observados diferentes graus de saturação nos solos e oscilações na profundidade do nível estático 
das águas subterrâneas rasas, após o período chuvoso, com reflexos diretos na variação temporal da infiltração.

Pitt et al. (2002) realizaram cerca de 150 testes de infiltração na área urbana de Birmingham, Alabama (EUA). Para solos arenosos foram obtidas as seguintes taxas de infiltração médias: $330 \mathrm{~mm} \mathrm{~h}^{-1}$ (solos não compactados) e $35 \mathrm{~mm} \mathrm{~h}^{-1}$ (solos compactados). Os solos argilosos apresentaram valores médios de $249 \mathrm{~mm} \mathrm{~h}^{-1} \mathrm{em}$ área com solos não compactados e secos e $5 \mathrm{~mm} \mathrm{~h}^{-1}$ em áreas com solos compactados secos e úmidos.

Zuquette \& Palma (2006) realizaram ensaios de infiltração na bacia do Córrego Vaçununga (SP). Os autores observaram que, embora a região apresente homogeneidade geológica, o comportamento hidrodinâmico sofre significativa influência do tipo de uso do solo, estágio evolutivo e das práticas de manejo.

Autores como Arruda (1984) e Pitt et al. (2002), observaram que os testes com infiltrômetros de duplo anel superestimaram a taxa de infiltração em comparação aos valores observados durante eventos chuvosos ou através de outros métodos de ensaio.

Para Libardi (1995), os solos com argilas expansivas, a textura, tamanho e disposição do espaço poroso, manejo do solo, estrutura mineralogia e umidade inicial do solo, são alguns dos fatores responsáveis pelas variações nos valores da taxa de infiltração da água na zona não saturada.

Diversos outros trabalhos, publicados na última década, tem analisado as propriedades físicas dos solos, compactação e a infiltração, dentre os quais se destaca: Cunha, et al., 2009; Paixão, et al., 2004; Coelho et al., 2000; Souza; Alves, 2003, Oliveira et al., 2010; De'Fossez, 2003, Souza, 2008 e Grego; Vieira, 2005.

Os solos da área de estudo (profundidade efetiva de $60 \mathrm{~cm}$ ), foram caracterizados como Argissolos Amarelos distróficos típicos, textura arenosa / média, com gradiente textural (relação B / A), que é da ordem de $2 \%$ argila. O gradiente textural é a relação da porcentagem de argila do horizonte B em comparação com a do horizonte A, e é calculado pela divisão da média aritmética da porcentagem de argila do horizonte B, não incluindo o sub-horizonte $\mathrm{BC}$ (anteriormente $\mathrm{B} 3$ ), pela média aritmética da porcentagem de argila do horizonte A.

Hipoteticamente, numa área de cultivo intensivo, como é o caso em estudo, além da variabilidade natural do solo, em função do processo de intemperização ocorrer de modo heterogêneo e descontínuo, as fontes decorrentes da ação antrópica devem exercer influência na taxa de infiltração das águas na zona não saturada. 
Neste estudo, não foram consideradas as variáveis associados às propriedades da própria água e do manejo adotado, as quais também interferem na taxa de infiltração.

\section{2 - MATERIAL E MÉTODOS}

A área de pesquisa, com 1,2 $\mathrm{km}^{2}$, está localizada no município de Capitão Poço, nordeste do Pará, nas nascentes da microbacia do rio Capitão Pocinho, entre as Latitudes Sul $01^{0} 49^{\prime} 58,9^{\prime \prime}$ e $1^{0} 49^{\prime} 22,4^{\prime \prime}$ e as Longitudes Oeste de Greenwich $53^{0}$ $12^{\prime} 07^{\prime \prime}$ e $53^{\circ} 11^{\prime} 27^{\prime \prime}$. Nesta região predomina o agroecossistema dos laranjais sobre o ecossistema urbano (IBGE, 2000). Capitão Pocinho é desprovido de saneamento básico o que provoca o uso de recursos hídricos de superfície e subterrâneos em nível individual (Figura 1A e Figura 1B).

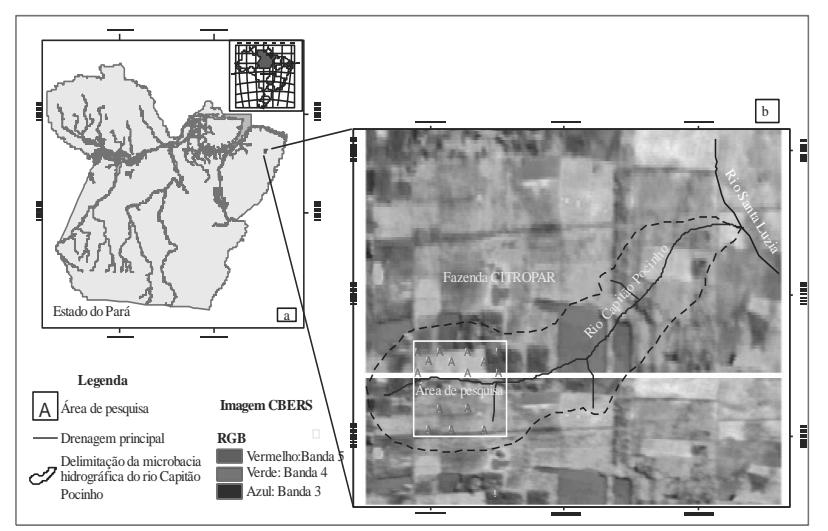

Figura 1. a Mapa indicando a posição do município de Capitão Poço, no Estado do Pará, onde está inserida a microbacia hidrográfica do rio Capitão Pocinho. b Localização da área de pesquisa delimitada pelo contorno retangular, posicionado na parte inferior esquerda da figura, na imagem CBERS. No interior desta figura (identificados por círculos), está à localização dos poços piezômetros ou de monitoramento perfurados na margem direita (PM04, PM05, PM06, PM07 e PM15) e esquerda (PM01, PM02, PM03, PM08, PM09, PM10, PM11, PM12, PM13 e PM14)

As medidas e coletas de materiais foram realizadas em áreas de agroecossistemas de cítrus (laranjal), no final do período chuvoso de 2009. Estas atividades foram realizadas em poços distribuídos regularmente numa malha em forma de losango, em diferentes classes de solos (Figura 2).

Para a caracterização do balanço hídrico foi utilizado o modelo de Thornthwaite; Mather (1955), tendo como parâmetros os dados diários de precipitação pluviométrica, temperatura e umidade relativa do ar, referentes ao período de 1980 a 2001, obtidos na 
estação climatológica da Embrapa Amazônia Oriental, na cidade de Capitão Poço. Na região predominam as seguintes classes climáticas: tropical chuvoso (classificação de Köppen) e úmido com ocorrência de pequena deficiência hídrica (classificação de Thornthwaite). Segundo Pacheco; Bastos (2001), ambas significam clima tropical sem ocorrência de inverno estacionário. As amplitudes térmicas são inferiores a $7{ }^{\circ} \mathrm{C}$. Nas horas de maior insolação, a temperatura fica em torno de $26^{\circ} \mathrm{C}$, enquanto que, durante a madrugada, a temperatura situa-se em torno de $23{ }^{\circ} \mathrm{C}$, com temperatura média anual de $26,2^{\circ} \mathrm{C}$.

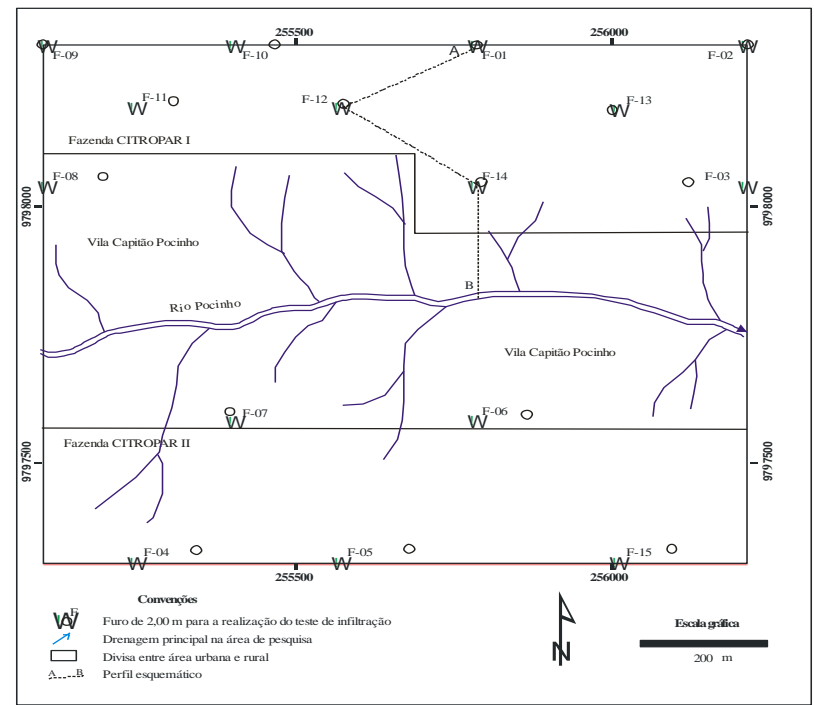

Figura 2. Detalhamento da área de pesquisa localizada no alto curso da microbacia do rio Capitão Pocinho. Posicionamento do perfil esquemático (Figura 3)

Estes poços foram distribuídos, geograficamente, em diferentes classes de solos e suas localizações e esquema pode ser observado nas Figuras 2 e 3.

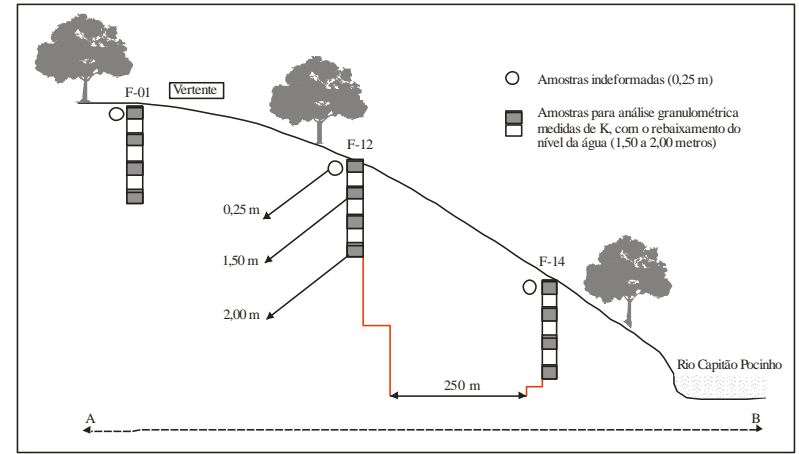

Figura 3. Perfil esquemático $\mathrm{AB}$ (Figura 1) mostrando o posicionamento, em profundidade, das amostras indeformadas e o intervalo onde foram realizados os ensaios de infiltração para a estimativa da condutividade hidráulica "in situ". 
A época mais chuvosa foi de janeiro a julho, enquanto que a menos chuvosa se estende de julho a dezembro, com déficit de água nos meses de agosto a dezembro. A ocorrência de chuva durante todo o ano condiciona o tipo de vegetação conhecida como floresta tropical úmida, visto que o mês de menor cota pluviométrica é superior a $50 \mathrm{~mm}$. Os resultados obtidos no balanço hídrico consideram o solo com a capacidade de retenção de $100 \mathrm{~mm}$ de água (Figura 4).

Para o período de 1980 a 2001, o total médio anual de excedente hídrico foi de 1.010,6 mm, com uma variação mínima em torno de $10 \mathrm{~mm}$ em julho e máxima a cerca de $270 \mathrm{~mm}$ em março. Enquanto que a deficiência hídrica superou a precipitação em outubro e novembro (Pacheco; Bastos, 2001).

A geologia predominante é formada por sedimentos terciários do Grupo Barreiras e Pós Barreiras, seguida por sedimentos aluvionares do Quaternário. O solo predominante é o Argissolo Amarelo Álico Tb A moderado, com textura média e argilosa, secundado por Neossolo Quartzarenico A fraco (EMBRAPA, 1997).

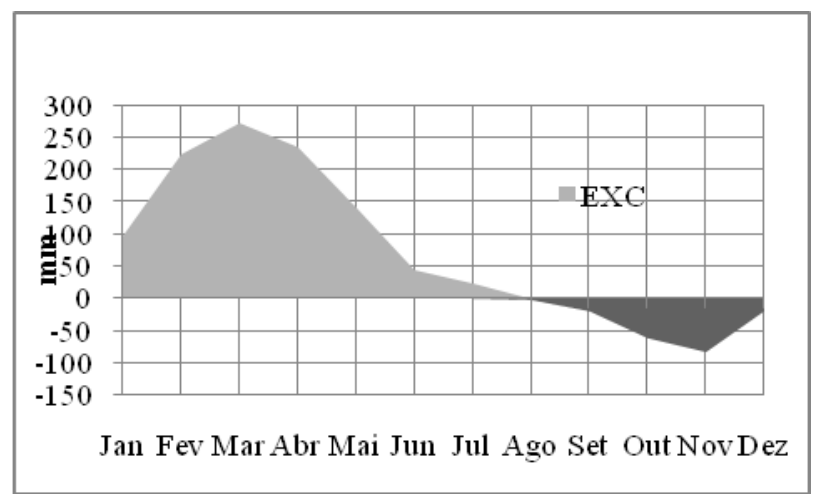

Figura 4. Distribuição anual dos excedentes e déficits hídricos obtidos no balanço, considerando retenção hídrica de $100 \mathrm{~mm}$ para a área de pesquisa. Embrapa Amazônia Oriental, Capitão Poço (1980 a 2001)

\subsection{Ensaio de infiltração na zona não saturada}

Os ensaios de infiltração foram realizados em quinze poços, através do método desenvolvido pela Associação Brasileira de Geologia e Engenharia - ABGE (1996), a uma profundidade que ultrapassou a exploração do sistema radicular do plantio de cítrus, na área de pesquisa. Esses ensaios foram realizados junto aos poços de monitoramento perfurados durante a pesquisa de campo (Figura 5). 


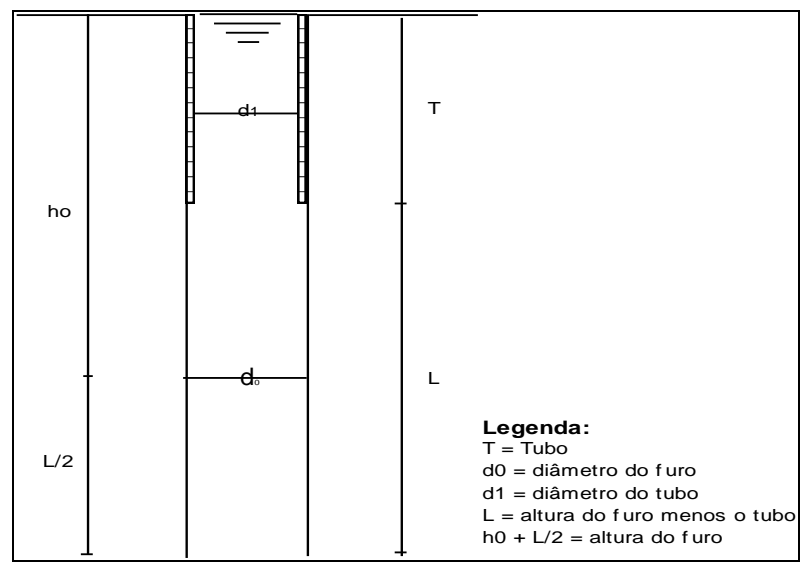

Figura 5. Ensaio de rebaixamento para cálculo da condutividade hidráulica na zona não saturada (ABGE, 1996)

Inicialmente, para a execução dos ensaios de infiltração, foram escavados poços com trado manual de $10 \mathrm{~cm}$ de diâmetro, até a profundidade de $200 \mathrm{~cm}$, sendo em seguida revestido com tubo PVC medindo $50 \mathrm{~cm}$ de comprimento e diâmetros interno e externo de $100 \mathrm{~mm}$ e $110 \mathrm{~mm}$, respectivamente. O nível d'água no poço foi mantido na entrada do tubo por cerca de 10 minutos para "saturação", tendo-se posteriormente iniciado a leitura das medidas de variação do nível de água. Para a conclusão do ensaio são recomendados mais de 30 minutos de observações (ABGE, 1996). O teste foi dado como concluído quando a taxa de infiltração mostrou valores semelhantes durante duas ou três leituras consecutivas.

Como as medidas de infiltração foram feitas com um só cilindro (tubo PVC), desconsiderou-se a movimentação lateral, que faz com que o raio médio da frente de molhamento $(R)$ exceda o raio do cilindro (r) ABGE (1996). Nos locais dos ensaios de infiltração, a profundidade do nível estático foi medida no poço de monitoramento perfurado às proximidades.

\subsection{Estimativa da condutividade hidráulica na zona não saturada e a determinação da taxa do fluxo vertical de infiltração}

A partir dos dados dos ensaios de infiltração observados no campo, foi possível obter a curva de infiltração e calcular a lâmina infiltrada utilizando-se a Eq. (1) (Horton, 1940). A lâmina infiltrada foi calculada objetivando estimar os valores de condutividade hidráulica dos sedimentos do meio não saturado. Para tal, considerou-se o aquífero livre como homogêneo e isotrópico. 


$$
f=f_{c}+\left(f_{o}-f_{c}\right) \cdot e^{-k . t}
$$

Onde:

$f$ = capacidade de infiltração no tempo $\mathrm{t}\left(\mathrm{mm} \mathrm{h}^{-1}\right)$;

$f_{0}=$ capacidade de infiltração inicial para $\mathrm{t}=0\left(\mathrm{~mm}^{-1} \mathrm{~h}\right)$;

$f_{c}=$ capacidade de infiltração final ( $\left.\mathrm{mm} \mathrm{h}-1\right)$;

$\mathrm{k}=$ constante para cada curva $\left(\mathrm{h}^{-1}\right) \mathrm{e}$;

$\mathrm{t}=$ tempo $(\mathrm{h})$.

Os parâmetros $f_{o}, f_{c}$ e k são parâmetros ligados ao tipo de solo. Solo Arenoso = baixo escoamento superficial e alta infiltração; Solo Franco Arenoso $=$ solos menos permeável; Solo Franco Argiloso = escoamento superficial acima da média; Solo Argiloso = pouco profundo e grande escoamento superficial (Horton, 1940).

A condutividade hidráulica do solo foi estimada através da Eq. (2), obtida do modelo determinado por Horton (1940).

$$
\mathrm{K}=\mathrm{f}_{0-} \mathrm{f}_{\mathrm{c} /} / \mathrm{F}_{\mathrm{c}}
$$

Onde:

$\mathrm{K}=$ condutividade hidráulica;

$\mathrm{f}_{\mathrm{o}}=$ capacidade de infiltração inicial $(\mathrm{L})$;

$\mathrm{f}_{\mathrm{c}}=$ capacidade de infiltração final e;

$\mathrm{F}_{\mathrm{c}}$ = área do gráfico da curva de infiltração;

Para o cálculo aproximado da área do gráfico da curva de infiltração foi usado para cada intervalo de tempo, uma área como se fosse um trapézio $F c i=(B+b) / 2 \times h, . F_{c}$ é o somatório de $\mathrm{F}_{\mathrm{ci}}$.

A finalidade da determinação da taxa do fluxo subterrâneo vertical foi estabelecer a estimativa da taxa de deslocamento dos possíveis contaminantes provindos de agrotóxicos utilizados na citricultura intensiva, que possam ter atingido as águas subterrâneas rasas. Para o cálculo da taxa linear média, utilizou-se a Eq. (3):

$$
v=K i / \eta
$$

Onde:

$v=$ taxa linear média da água subterrânea $\left[\mathrm{L} \mathrm{T}^{-}\right]$;

$K=$ condutividade hidráulica $\left[\mathrm{L} \mathrm{T}^{-}\right]$;

$i=$ gradiente hidráulico $[\mathrm{adm}] \mathrm{e}$;

$\eta=$ porosidade total; 
A porosidade total é considerada como equivalente à porosidade efetiva para fluxo $\left(\mathrm{n}_{\mathrm{ef}}\right)$.

\section{3 - Determinação da porosidade}

Para a determinação da porosidade foram coletadas 15 amostras indeformadas. Essas amostras, de volume conhecido, foram secas em estufa a $105^{\circ} \mathrm{C}$ até atingirem um peso constante. Após a secagem, as amostras foram submersas em um volume de água conhecido, permanecendo ali até haver a total saturação. Medindo-se o volume de água necessário para que ocorresse a saturação completa, determinou-se diretamente a porosidade através da razão entre o volume de vazios e o volume total (Bear e Verruijt, 1990), através da Eq. (4).

$$
\eta=\mathrm{V}_{\mathrm{vi}} / \mathrm{V}
$$

Onde:

$\eta=$ porosidade total;

$\mathrm{V}_{\mathrm{vi}}=$ volume de vazios e;

$\mathrm{V}=$ volume total.

Os resultados foram analisados efetuando-se a estatística descritiva.

\section{4 - Análise granulométrica dos sedimentos do meio não saturado}

As amostras de sedimentos, para análise granulométrica, foram coletadas a cada 0,50 $\mathrm{m}$ até atingir o nível estático, utilizando-se um trado manual de 101,6 mm (4"). A caracterização obedeceu às seguintes etapas: 1) coleta do sedimento; 2) homogeneização do material; 3) quarteamento; 4) armazenamento em sacos plásticos e; 5) identificação da amostra e encaminhamento para análise granulométrica. Este método está normatizado pela NBR 13895 (ABNT, 1997). A análise granulométrica foi realizada através do método do densímetro (Gee; Or, 2002).

\section{5 - Estimativa da taxa de infiltração na zona não saturada}

A Eq. (5) descreve a taxa de infiltração na zona não saturada (v), estimada com base na equação matemática de taxa da água subterrânea, derivada da combinação entre a Lei de Darcy e a equação da taxa hidráulica (Heath,1983): 


$$
v=(K / \eta) x(d h / d L)
$$

Sendo:

$v=$ taxa de fluxo;

$K=$ condutividade hidráulica;

$\eta=$ porosidade efetiva $\mathrm{e}$;

$d h d L^{-1}=$ gradiente hidráulico

Para o cálculo do escoamento vertical na zona insaturada utilizou-se $\mathrm{dh} . \mathrm{dL}^{-1}=1$.

\section{6 - Determinação do gradiente hidráulico}

A Eq. (6) mostra o cálculo do gradiente hidráulico (i), que é um número adimensional que representa a inclinação da superfície potenciométrica, ao admitir-se que se cumpre a Lei de Darcy, e corresponde à razão entre as variações de carga hidráulica e o comprimento percorrido, no sentido do fluxo (Feitosa, 2008).

$$
i-h_{1}-h_{2 x} i / d
$$

Sendo:

$i=$ gradiente hidráulico;

$h_{1}=$ cota da isopieza ou do poço a montante;

$h_{2}=$ cota da isopieza ou do poço a jusante e;

$d=$ distância entre as duas isopiezas ou dos poços considerados.

\section{3 - RESULTADOS E DISCUSSÕES}

As representações gráficas dos resultados dos ensaios de infiltração em sedimentos inconsolidados do meio não saturado, pelo método do rebaixamento acima do nível estático, podem ser visualizadas na Figura 7. Os poços F-01, F-02, F-03, F-09, F-10, F-11, F-12 e F-13, estão situados na margem esquerda e os poços F-04, F-05, F-06, F07 e F-15 na margem direita das nascentes da microbacia do rio Capitão Pocinho.

Os valores do meio não saturado de condutividade hidráulica saturada $(\mathrm{K})$ variaram dentre $6,75 \mathrm{~mm} \mathrm{~h}^{-1}$ a 7,05 $\mathrm{mm} \mathrm{h}^{-1}$ e a porosidade variou em média entre $38 \%$ e $39 \%$, respectivamente, na margem direita e esquerda das nascentes do rio Capitão Pocinho. Estes valores são compatíveis com as características dos sedimentos que compõem a zona não saturada do aquífero livre Barreiras (Araújo, 2001). Embora os valores 
obtidos de condutividade hidráulica $(\mathrm{K})$ tenham sido pontuais, estes podem ser considerados representativos para a área de estudo, tendo em vista as similaridades da geologia de superfície e subsuperfície das unidades geológicas aflorantes. Na cidade de São Paulo (SP), estudos desenvolvidos por Vernier; Hirata (2000), mostraram que entre as características propícias à infiltração com taxas elevadas são: área plana, solos bastante ricos em matéria orgânica e sombreados por árvores (plantio de cítrus). Estudos realizados por Borges et al. (1997) no município de Uberlândia (MG), indicam que a capacidade de infiltração é inversamente proporcional a quantidade de escoamento superficial.

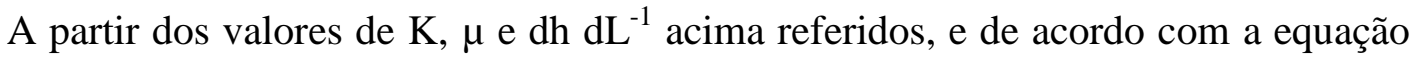
5 , tem-se que a taxa média de infiltração da água na zona não saturada está compreendida entre dois valores abaixo calculados, para a área da margem direta e da margem esquerda do rio Capitão Pocinho, respectivamente: $v=(6,75 \times 0,38) 01=2$, $57 \mathrm{~mm} \mathrm{~h}^{-1}$ (margem direita do rio Capitão Pocinho) e v $=(7,05 \times 0,39) 01=2,75 \mathrm{~mm}$ $\mathrm{h}^{-1}$ (margem esquerda do rio Capitão Pocinho).

Considerando-se a profundidade média do nível estático de $6,26 \mathrm{~m}$, medido no final do período chuvoso nos poços localizados na margem esquerda do rio Capitão Pocinho (F-01, F-02, F-03, F-08, F-09, F-10, F-11, F-12, F-13 e F-14) e a taxa média calculada de infiltração de $2,75 \mathrm{~mm} \mathrm{~h}^{-1}$, estima-se em torno de três meses o tempo para que os agrotóxicos atinjam as águas subterrâneas rasas. Por outro lado, levando-se em conta a profundidade média do nível estático de 5,08 $\mathrm{m}$, medida na mesma época nos poços de monitoramento e, a taxa média de infiltração na margem direita do rio Capitão Pocinho, estimada em 2,57 $\mathrm{mm} \mathrm{h}^{-1}$, os contaminantes oriundos dos agrotóxicos podem atingir a superfície do lençol freático em tempo da ordem quatro meses.

A análise da variação da taxa de infiltração e da textura do solo sugere que ocorreu uma correlação direta entre os dois parâmetros estudados, em toda a área de pesquisa. Não foi possível analisar a influência da umidade inicial do solo e a elevação e distância do rio com relação à variação da taxa de infiltração. Pitt et al. (2002) encontraram a taxa de infiltração média de $5 \mathrm{~mm} \mathrm{~h}^{-1}$, em área com solo argiloso compacto seco e úmido. 
A infiltração das águas na zona não saturada se processa de uma maneira mais efetiva nos poços F-07, F-12 e F-15, possivelmente, devido ao escoamento superficial mais lento. Ressalte-se que nestas áreas a declividade do terreno é menor do que $2 \%$.

\section{4 - CONCLUSÕES}

1) Na zona não saturada do aquífero livre Barreiras a condutividade hidráulica saturada $(\mathrm{K})$ variou dentre $6,75 \mathrm{~mm} \mathrm{~h}^{-1}$ a 7,05 $\mathrm{mm} \mathrm{h}^{-1}$ e a porosidade dos sedimentos, em média, entre $38 \%$ e $39 \%$, respectivamente, na margem direita e esquerda das nascentes do rio Capitão Pocinho.

2) Para a área de pesquisa, onde se desenvolve a atividade agrícola, foi obtida a taxa média de infiltração de $3,0 \mathrm{~mm} \mathrm{~h}^{-1}$ em solo seco.

3) Em função da profundidade do nível estático estima-se em torno de três meses o tempo médio para que os agrotóxicos atinjam as águas subterrâneas rasas, na margem esquerda do rio Capitão Pocinho. Na margem direita do rio Capitão Pocinho, os contaminantes oriundos dos agrotóxicos podem atingir a superfície do lençol freático em tempo da ordem de quatro meses.

4) Ao se correlacionar a taxa de infiltração com a proteção das águas subterrâneas rasas, observou-se que as nascentes do rio Capitão Pocinho são susceptíveis à contaminação por agrotóxicos utilizados na citricultura intensiva.

5) Os resultados obtidos neste trabalho, poderão contribuir para a análise da contaminação das águas subterrâneas rasas, por agrotóxicos, nos pomares de cítrus que abrangem a microbacia hidrográfica do rio Capitão Pocinho.

\section{AGRADECIMENTOS}

Agradecemos o apoio financeiro do Conselho Nacional de Desenvolvimento Científico e Tecnológico - CNPq (Proc. 484848/2007-0) - Contaminação de Recursos Hídricos em Área de Cultivo de Cítrus (Cítrus sinensis L) em grande escala na Amazônia oriental, e as empresas Cítricas do Pará (CITROPAR) e Companhia de Pesquisa e Recursos Minerais (CPRM), pela liberação de pessoal técnico e apoio logístico/financeiro, para a realização deste estudo nos trabalhos de campo. Ao Centro de Pesquisa Agroflorestal da Amazônia (CPATU-EMBRAPA), pela concessão dos dados termo pluviométricos. 


\section{REFERÊNCIAS BIBLIOGRÁFICAS}

ABGE - Ensaios de permeabilidade em solos, orientações para sua execução no campo $3^{0}$ Edição. Associação Brasileira de Geologia de Engenharia. Boletim 04. São Paulo. SP. 42p. 1996.

ABNT - Associação Brasileira de Normas Técnicas. NBR 13895 Construção de poços de monitoramento e amostragem. 21p. 1997.

ARAÚJO, P. P. Variações sazonais dos componentes nitrogenados, em Aquífero livre na zona urbana de Santa Isabel do Pará, Nordeste do Estado do Pará. Belém, Pa: CPGG, UFPA, 2001.113p. Dissertação de Mestrado

BEAR, J.; Verruijt, A. Modeling Groundwater Flow and Pollution. D. Riedel Publishing Company. 1990.

BORGES, M. S.; Angélica, R. S. Levantamento geológico da Ilha do Mosqueiro Estado do Pará. Belém: Universidade Federal do Pará, Projeto Fosfatos na Amazônia, 34 p. 1986.

COELHO, R.D.; Miranda, J.H.; Duarte, S.N. Infiltração da água no solo: parte I infiltrômetro de anéis versus infiltrômetro de aspersores. Revista Brasileira de Engenharia Agrícola e Ambiental. Campina Grande, PB. v.4, n.2, p.137-141. 2000.

CUNHA, J.L.X.L.; Albuquerque, A.W.; SILVA, C.A.; ARAÚJO, E.; JUNIOR, R.B.S. Taxa de infiltração da água em um latossolo amarelo submetido ao sistema de manejo plantio direto. Revista Caatinga. Mossoró, RN. v.22, n.1, p.199-205. 2009.

DE'FOSSEZ, P.; Richard, G.; Boizard, H.; O’Sullivan, M. F. Modeling change in soil compaction due to agricultural traffic as function of soil water content. Geoderma, v.116, n.1-2, p.89-105. 2003.

EMBRAPA - Empresa Brasileira de Pesquisa Agropecuária. Manual de métodos de análise de solo. 2.ed. Rio de Janeiro: EMBRAPA/CNPSO. 212 p. 1997.

FEITOSA, A.C. et al. Hidrogeologia: conceitos e aplicações/organização. 3 ed. Ver. E ampl. Rio de Janeiro: CPRM: LABHID, 812 p. 2008.

GEE, G.W.; Or, D. Particle-size analysis. In: Dane, J.H.; Topp, G.C. (Ed.). Methods of soil analysis. 3rd ed. Madison: Soil Science Society of America, pt. 4: Physical methods, p. 255-293. (Book Series, 5). 2002.

GREGO, C.R.; Vieira, S.R. Variabilidade espacial de propriedades físicas do solo em uma parcela experimental. Revista Brasileira de Ciência do Solo, v.29, p.169-177. 2005. 
HORTON, R. E. An approach toward a physical interpretation of infiltration capacity soil. Science Society of American Proceeding, v.4, p.399-417, 1940 [ Links ]

IBGE - Instituto Brasileiro de Geografia e Estatística. Censo Demográfico 2000.

KHAN, S.U. Pesticides in the soil environment. Amsterdam: Elsevier Scientific, 240p. 1980.

LIBARDI, P.L. (Ed.). Dinâmica da água no solo. Piracicaba: ESALQ-USP. 497p. 1995.

OLIVEIRA V.S; Rolim, M.M; Vasconcelos, R.F.B. Costa, Y.D.J.; Pedrosa, E.M.R. Compactação de um Argissolo Amarelo distrocoeso submetido a diferentes manejos. Revista Brasileira de Engenharia Agrícola e Ambiental, v.14, n.9, p.914-920. 2010. PACHECO, N. A.; Bastos, T. X. Caracterização climática do Município de Capitão Poço, PA. Belém-PA: Embrapa Amazônia Oriental, 18p. (Documentos, 87). 2001. PAIXÃO, F. J. R.; Andrade, A. R. S.;Azevedo, C. A. V.; Silva, J. M.; Costa, T. L.; Feitosa, R. M. Estimativa da Infiltração da água no solo através de modelos empíricos e funções não lineares. Revista de Biologia e Ciência da Terra. Campina Grande, PB. v.5, n.1. 2004.

PITT, R.; Chen, S.; Clark, S. Compacted Urban Soils Effects on Infiltration and Bioretention Stormwater Control Designs. In: STRECKER, E.W.; HUBER, W.C. Global Solutions for Urban Drainage. Proceedings of the Ninth International Conference on Urban Drainage. Portland, Oregon, USA. 2002.

SOUZA, E.S. et al. Variabilidade espacial dos parâmetros hidrodinâmicos de duas parcelas agrícolas no estado da Paraíba. Rev. Bras. Ciênc. Solo [online]. vol.32, n.5 ISSN 0100-0683. 2008.

SOUZA, Z. M.; Alves, M.C. Movimento de água e resistência à penetração em um Latossolo Vermelho distófico de cerrado. Revista Brasileira de Engenharia Agrícola e Ambiental, v.7, p.18-23. 2003.

THORNTHWAITE, C. W.; Mather, J. R. The water balance. Publications in Climatology. New Jersey: Drexel Institute of Technology, 104p. 1955.

VERNIER, C.; Hirata R. Contaminação da Água Subterrânea por Nitrato no Parque Ecológico do Tietê - SP - BR. In: Joint World Congress on Groundwater, $1^{\mathrm{ST}}$, Anais. Fortaleza. ABAS, 2000.

ZUQUETTE, L.V.; Palma, J.B. Avaliação da condutividade hidráulica em área de recarga do aquífero Botucatu, Rev. Esc. Minas vol.59 nº . 1, Ouro Preto Jan./Mar. 2006. 